\title{
Activity-Dependent Trafficking and Dynamic Localization of Zipcode Binding Protein 1 and $\beta$-Actin mRNA in Dendrites and Spines of Hippocampal Neurons
}

\author{
Dhanrajan M. Tiruchinapalli, ${ }^{1}$ Yuri Oleynikov, ${ }^{2}$ Sofija Kelič, ${ }^{1}$ Shailesh M. Shenoy, ${ }^{2}$ Adam Hartley, ${ }^{1}$ Patric K. Stanton, ${ }^{1}$ \\ Robert H. Singer, ${ }^{2}$ and Gary J. Bassell ${ }^{1}$ \\ ${ }^{1}$ Department of Neuroscience, Rose F. Kennedy Center for Research in Mental Retardation and Human Development, and ${ }^{2}$ Department of Anatomy and \\ Structural Biology, Albert Einstein College of Medicine, Bronx, New York 10461
}

\begin{abstract}
RNA binding proteins may be important mediators of the activity-dependent transport of mRNAs to dendritic spines of activated synapses. We used fluorescence microscopy and digital imaging techniques applied to both fixed and live cultured hippocampal neurons to visualize the localization of the mRNA binding protein, zipcode binding protein 1 (ZBP1), and its dynamic movements in response to $\mathrm{KCl}$-induced depolarization at high spatial and temporal resolution. With the use of immunofluorescence, image deconvolution, and three-dimensional reconstruction, ZBP1 was localized in the form of granules that were distributed in dendrites, spines, and subsynaptic sites. $\mathrm{KCl}$ depolarization increased the dendritic localization of ZBP1 that was not attributed to an increase in ZBP1 expression. Live cell imaging of single cells before and after perfusion of $\mathrm{KCl}$ revealed the rapid and directed efflux of ZBP1 granules from the cell body into dendrites in a proximo-distal gradient. High-speed imaging of enhanced green fluorescence protein-ZBP1 granules revealed rapid anterograde and retrograde movements in dendrites as well as dynamic movements in dendritic spines. A population of ZBP1 granules colocalized with $\beta$-actin mRNA, and their spatial association in dendrites was increased by $\mathrm{KCl}$ depolarization. The NMDA receptor antagonist AP-5 impaired the dendritic localization of ZBP1 and $\beta$-actin mRNA and inhibited the KCl-induced transport of ZBP1. The activity-dependent trafficking of ZBP1 and its dynamic movements within dendritic spines provide new evidence to implicate RNA binding proteins as regulators of mRNA transport to activated synapses in response to synaptic activity.
\end{abstract}

Key words: mRNA localization; mRNA binding protein; zipcode binding protein; $\beta$-actin mRNA; dendritic spines; NMDA receptors

\section{Introduction}

The dendritic transport and localization of specific mRNAs to dendritic spines of excitatory synapses have been hypothesized to provide an important mechanism to influence synapse development and plasticity (Job and Eberwine, 2001; Steward and Schumann, 2001). Several examples of activity-dependent localization of specific mRNAs in dendrites of cultured neurons (Tongiorgi et al., 1997; Mori et al., 2000; Rook et al., 2000) and in vivo (Steward et al., 1998; Steward and Worley, 2001) provide compelling support for the idea that glutamatergic signaling pathways important for long-term plasticity may regulate dendritic mRNA transport and their docking at postsynaptic sites. Despite the above inferences that specific mRNAs are localized postsynaptically within dendritic spines, direct microscopic observations in hippocampal neurons have been lacking. Evidence for the synaptic localization of specific mRNAs is derived mainly from biochemical studies using synaptosomal fractions (Chicurel et al., 1993; Rao and Steward, 1993). Although this approach has provided new insight into synaptic mechanisms that regulate mRNA transla-

Received Aug. 14, 2002; revised Jan. 9, 2003; accepted Feb. 5, 2003.

This work was supported by National Institutes of Health Grants GM55599 and NS39641 (to G.J.B.) and AR41480 (to R.H.S.). We thank Kim Farina for antibody to ZBP1.

Correspondence should be addressed to Dr. Gary J. Bassell, Department of Neuroscience, Rose F. Kennedy Center for Research in Mental Retardation and Human Development, 1410 Pelham Parkway, Bronx, NY 10461. E-mail: bassell@aecom.yu.edu.

Copyright $\odot 2003$ Society for Neuroscience $\quad 0270-6474 / 03 / 233251-11 \$ 15.00 / 0$ tion (Bagni et al., 2000; Scheetz et al., 2000; Huang et al., 2002), it does not allow for study of how mRNAs become localized to synapses, which is a dynamic and regulated process that begins hundreds of microns away in the cell body or even the nucleus.

The molecular mechanism of mRNA localization to distal compartments in most polarized cells involves the recognition of cis-acting sequences by mRNA binding proteins that direct their selective targeting to distinct intracellular compartments (Kloc et al., 2002). By binding to specific cis-acting sequences, an RNA binding protein may serve as an adapter between the mRNA and the machinery involved in cytoskeletal-based transport (Bassell and Singer, 2001). The mRNA binding proteins involved in the sequence-specific localization of mRNAs in dendrites and postsynaptic sites are unknown. A major challenge is to identify mRNA binding proteins that exhibit dynamic and activitydependent movements into dendritic spines, the actin-rich protrusions from dendrites that serve as the major postsynaptic locus of excitatory innervation and plasticity (Harris and Kater, 1994). To accomplish this task requires the application of high-resolution microscopy to visualize the spatial relationship between mRNA binding proteins and specific mRNAs, simultaneous with the identification of synaptic markers and preservation of spine morphology.

We have focused on the mRNA binding protein, zipcode binding protein 1 (ZBP1), which binds a 54 nucleotide (nt) localization sequence termed "zipcode" in the 3 '-untranslated region ( $3^{\prime}$-UTR) of $\beta$-actin mRNA. The interaction between ZBP1 and the $\beta$-actin zipcode is required for $\beta$-actin mRNA localiza- 
tion to the leading edge of cultured chick embryo fibroblasts (Ross et al., 1997) and developing neurites and growth cones of cultured chick forebrain neurons (Zhang et al., 2001). The expression, localization, and regulation of ZBP1 in differentiated neurons have not been studied previously. In this study we used high-resolution fluorescence and digital imaging methods to visualize the localization of ZBP1 and $\beta$-actin mRNA granules, their spatial relationship in dendrites and spines, and the effect of $\mathrm{KCl}$ depolarization. In live neurons the ZBP1 granules exhibited rapid, bidirectional movements in dendrites and spines. Neuronal depolarization by $\mathrm{KCl}$ induced a rapid efflux of ZBP1 from the cell body into dendrites. The activity-dependent trafficking of $\mathrm{ZBP} 1$ in dendrites and spines is consistent with a probable role of ZBP1 as a trans-acting factor involved in the selective targeting of mRNAs to postsynaptic sites within dendritic spines in response to synaptic activity.

\section{Materials and Methods}

Hippocampal culture and drug treatments. By following the method of neuronal culture for embryonic rat hippocampus [embryonic day 19 (E19)] detailed in Goslin and Banker (Goslin et al., 1998), we dissociated cells with trypsin and plated them at low density $\left(90,000 \mathrm{cells} / \mathrm{cm}^{2}\right)$ on poly-L-lysine-coated $(1.0 \mathrm{mg} / \mathrm{ml})$ coverslips. The coverslips were inverted on a plate of astrocytes and grown as a coculture with defined media containing N2 supplements. After 2 weeks the neurons were fixed in paraformaldehyde ( $4 \%$ in $1 \times$ PBS with $5 \mathrm{~mm} \mathrm{MgCl}_{2}$ ) for $20 \mathrm{~min}$ at room temperature.

For drug treatments $\mathrm{KCl}$ was added to the $\mathrm{N} 2$ culture medium (final concentration, $20 \mathrm{~mm}$ ) for $15 \mathrm{~min}$ before fixation. Neurons also were pretreated for 15 min with the NMDA receptor antagonist D-2-amino5-phosphonopentanoic acid (AP-5, $100 \mu \mathrm{M})$ and then stimulated with $\mathrm{KCl}(20 \mathrm{~mm}, 15 \mathrm{~min})$ in the presence of AP-5. Cells also were treated with AP-5 alone ( $20 \mu \mathrm{M}, 15 \mathrm{~min})$ before fixation.

In situ hybridization with digoxigenin-labeled probes. Four aminomodified oligonucleotides (50 nt) complementary to 3'-UTR sequences of rat $\beta$-actin mRNA were synthesized on a DNA synthesizer and chemically labeled by using digoxigenin succinimide ester (Roche Molecular Biochemicals, Indianapolis, IN) as described previously (Bassell et al., 1998). Probes were isoform-specific for $\beta$-actin and were not homologous to $\gamma$-actin. In situ hybridization for $\beta$-actin mRNA was completed as previously described (Bassell et al., 1998). As negative controls, digoxigenin-labeled oligonucleotide probes were hybridized with $100 \times$ excess of unlabeled oligos. Alternatively, oligos for LacZ were used. These negative controls did not reveal either fluorescent signal or granules. The digoxigenin-labeled oligonucleotide probes were detected by immunofluorescence with the use of Cy3-conjugated monoclonal antibody to digoxigenin and $\mathrm{Cy} 3$-conjugated anti-mouse antibody (Jackson ImmunoResearch, West Grove, PA) as described previously (Zhang et al., 1999). Coverslips were mounted with Gelvatol with $n$-propyl gallate (6 $\mathrm{mg} / \mathrm{ml}$ ) as an anti-bleaching agent.

Immunofluorescence. Endogenous proteins were detected in cultured hippocampal neurons after fixation in 4\% paraformaldehyde for $15 \mathrm{~min}$ at room temperature by using the following antibodies and reagents. F-actin was detected with phalloidin conjugated to Alexa 488 fluorochrome (Molecular Probes, Eugene, OR). Rabbit polyclonal antibody to full-length recombinant chick ZBP1 (provided by Kim Farina, Albert Einstein College, Bronx, NY) was detected by using a secondary antibody conjugated with Cy3 (Jackson ImmunoResearch). Monoclonal antibodies were used to detect MAP2 (Sigma, St. Louis, MO) and synaptophysin (Sigma). All secondary antibodies were affinity-purified donkey antibodies to mouse or rabbit IgG conjugated to a fluorochrome (Jackson ImmunoResearch). Antibody incubations were for $1 \mathrm{hr}$ at room temperature in Tris-buffered saline (TBS) with BSA (1\%) and Triton X-100 $(0.1 \%)$, followed by several washes in the above TBS buffer on a rotary shaker. Coverslips were mounted on glass slides with Gelvatol to which $n$-propyl gallate $(6 \mathrm{mg} / \mathrm{ml})$ was added as an anti-bleaching agent.

Fluorescence microscopy, digital imaging for quantitative analysis, and three-dimensional reconstruction. Cells were viewed with an Olympus AX Provis microscope equipped with a $60 \times 1.4$ numerical aperture Plan Apo objective, $100 \mathrm{~W}$ mercury arc lamp, and HiQ bandpass filters (Chroma Technology, Brattleboro, VT). Images were captured with a cooled CCD CH-350 (502) camera (Roper Scientific, Tucson, AZ) with a Uniblitz 35 mm shutter and were processed with the IPLab 3.5 acquisition software (Scanalytics, Fairfax, VA). Dendritic morphology of the neurons was selected and imaged by using the phalloidin stain such that the user was blind to the signal for ZBP1 and $\beta$-actin mRNA. The filter set was changed automatically, and images of $\beta$-actin mRNA (in situ hybridization) and ZBP1 (immunofluorescence) were acquired in a $z$-series (11 sections, $0.2 \mu \mathrm{m}$ steps). Quantitative analysis of mRNA and protein localization within dendrites were calculated as mean pixel fluorescence intensity. A region of interest (ROI) $\sim 50 \mu \mathrm{m}$ in length and several pixels wide was traced, and the total fluorescence intensity was divided by its area. The analysis was done by using the same ROI coordinates in six in-focus sections from the middle of a $z$-series. Each histogram that is shown reflects a combined quantitative analysis of 45 dendrites (one dendrite per cell, 15 dendrites per experiment, three experiments).

Neurons labeled by triple-label fluorescence were imaged in each channel along the $z$-axis and deconvolved by using an acquired point spread function (Power Microtome, Scanalytics). Images were thresholded in IPLab to remove noise and enhance the contrast of structures of interest, and stacks were superimposed and registered. Volume rendering and three-dimensional (3-D) reconstruction were performed with Imaris software (Bitplane AG, Zurich, Switzerland).

Western blot. Hippocampal cultures grown on dishes were washed in cold PBS before being lysed in buffer containing $50 \mathrm{~mm}$ Tris- $\mathrm{HCl}, \mathrm{pH} 7.5$, $15 \mathrm{~mm} \mathrm{NaCl}, 1 \% \mathrm{NP}-40,0.5 \%$ sodium deoxycholate, and $0.002 \mu \mathrm{l} / \mathrm{ml}$ complete protease inhibitor mixture (Roche Bioscience, Palo Alto, CA). Total protein concentration was estimated by the bicinchoninic acid (BCA) method (Pierce, Rockford, IL). Then $25 \mu \mathrm{m}$ of protein was resolved by $8-10 \%$ SDS-PAGE, and fractionated proteins were transferred to Hybond ECL nitrocellulose membrane (Amersham Biosciences, Arlington Heights, IL), using a semi-dry blotter. ZBP1 was detected with a rabbit antibody to the full-length chick ZBP1. Monoclonal antibody to $\beta$-tubulin was used as a loading control for normalization (Sigma). The membrane was washed and incubated with peroxidase-conjugated goat anti-rabbit IgG (Jackson ImmunoResearch), and the signal was developed with ECL detection reagents (Amersham Biosciences). Bands on the exposure film were scanned, and the optical densities were analyzed quantitatively (Scion Image, Frederick, MD).

For drug treatments $\mathrm{KCl}$ was added to the $\mathrm{N} 2$ culture medium (final concentration, $20 \mathrm{~mm}$ ) for $15 \mathrm{~min}$ before lysis. Neurons also were pretreated for $15 \mathrm{~min}$ with the NMDA receptor antagonist AP-5 $(100 \mu \mathrm{M})$ and then stimulated with $\mathrm{KCl}(20 \mathrm{~mm}, 15 \mathrm{~min})$ in the presence of AP-5. Cells also were treated with AP-5 alone ( $20 \mu \mathrm{M}, 15 \mathrm{~min})$ before fixation. Neurons also were pretreated with cycloheximide (10 $\mu \mathrm{M}, 15 \mathrm{~min})$, and then $\mathrm{KCl}$ was added $(20 \mathrm{~mm}, 15 \mathrm{~min})$. Neurons also were treated with cycloheximide alone (10 $\mu \mathrm{M}, 15 \mathrm{~min})$ before lysis.

EGFP-ZBP1 transfections and live cell imaging. Rat hippocampal neurons were transfected with the chick ZBP1 coding sequence (Ross et al., 1997) that was inserted into the downstream cloning site of enhanced green fluorescence protein (EGFP) in the p-EGFP-C1 expression vector with a cytomegalovirus promoter (BD Biosciences, San Jose, CA), using the lipid reagent Lipofectamine 2000 (Invitrogen, San Diego, CA), and were allowed to express for $8 \mathrm{hr}$. Coverslips with transfected neurons were transferred to a closed Bioptechs FCS2 chamber (Bioptechs, Butler, PA) in Leibovitz's L-15 medium (Invitrogen) with N2 supplement. Images of live neurons were acquired with an Olympus BX60 microscope $60 \times 1.4$ numerical aperture Plan Apo objective and TILL Photonics (Grafeling, Germany) polychrome II monochromator with Imago-QE CCD (Imago Scientific Instruments, Madison, WI) and TILL vision software. Cells were imaged at an exposure rate of $0.424 \mathrm{msec}$ for each frame. Frames were acquired (resolution of $111.7 \mathrm{~nm} /$ pixel), inverted, and scaled with IPLab 3.5 acquisition software (Scanalytics). A macro was written that outputs the $x$ and $y$ coordinates of the granule centroid and the frame number into a tab-delimited text file that was used in Microsoft Excel to calculate granule velocities between frames. 

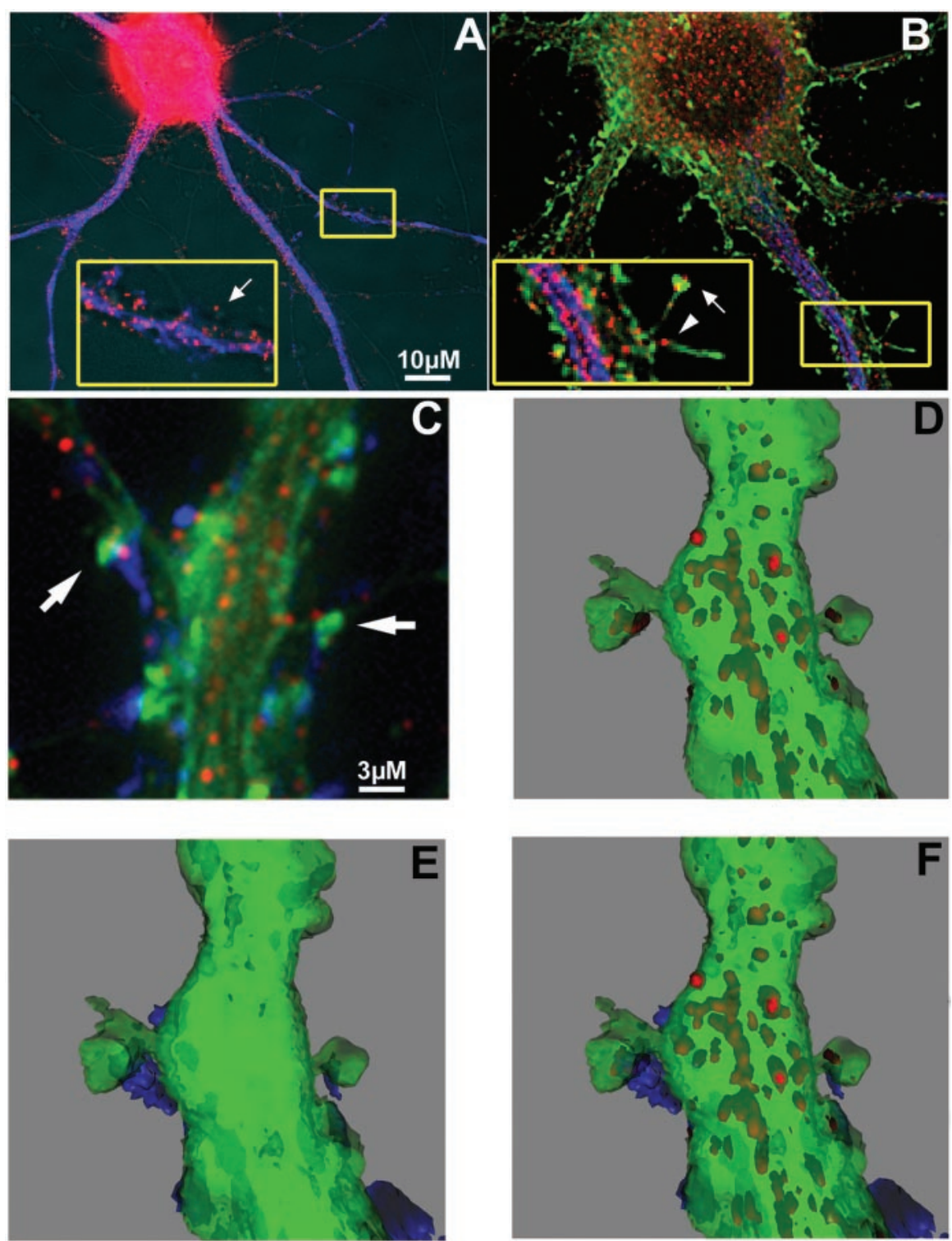

Figure 1. ZBP1 granules are localized in dendrites and beneath synapses of dendritic spines of cultured hippocampal neurons A, Double-label immunofluorescence detection of ZBP1 (red) and microtubule-associated protein MAP2 (blue) overlaid on DIC optics. ZBP1 was abundant in the cell body and distributed throughout dendrites in the form of granules, which frequently were observed to extend beyond the microtubule-rich region of the dendritic shaft and into spine-like protrusions [small box is enlarged (arrow)]. B, Triple-label fluorescence of ZBP1 (red), MAP2 (blue), and F-actin detected with phalloidin (green). ZBP1 granules were localized in the neck and head of spine-like structures (arrow, enlarged inset) and filopodia (arrowhead, enlarged inset). $C$, Triple-label fluorescence of ZBP1 (red), synaptophysin (blue), and F-actin detected with phalloidin (green). Use of conventional digital imaging and color overlay show colocalization (arrows) of ZBP1 granules (red) with synaptophysin (blue) and phalloidinlabeled spines (green). D-F, Three-dimensional reconstruction of a deconvolved z-series of the region shown in C depicts a track-like or clustered arrangement of several ZBP1 (red) granules in the dendritic shaft (video 1, available at www.jneurosci.org). A cluster of ZBP1 granules also is observed on one side of a large spine (green) beneath a large presynaptic contact (blue) along the spine neck in a crevasse between the dendritic shaft and the bulbous spine head. D, ZBP1 (red) and phalloidin (green) merged. $E$, Synaptophysin (blue) and phalloidin (green) merged. F shows all three channels merged.

\section{Results}

Visualization of ZBP1 granules in dendrites, actin-rich spines, and subsynaptic loci with the use of high-resolution fluorescence microscopy

Cultured rat hippocampal neurons were used as a model system to determine whether ZBP1 was localized to dendrites and subsynaptic sites within spines. Neurons were cultured for 2 weeks to allow for differentiation of axons and dendrites, compartmentalization of microtubule-associated proteins, elaboration of den- dritic spines, and formation of synapses (Goslin et al., 1998). Hippocampal cultures have been shown previously at the ultrastructural level to reveal axodendritic synapses formed en passant and polyribosomes at the base of dendritic spines (Bartlett and Banker, 1984). Triplelabel immunofluorescence microscopy and digital imaging analysis of optical sections were used to visualize dendrites, spines, and the synaptic contacts made between them at high resolution.

Immunofluorescence detection of microtubule-associated protein MAP2 (high molecular weight isoform) was used to label dendrites (Fig. 1A). MAP2 was distributed uniformly throughout the dendritic shaft and was not observed to enter spines or filopodia (Fig. $1 A$, inset, arrow). ZBP1 was abundant within the cell body and extended into MAP-2labeled dendrites in the form of granules (Fig. 1A, red). ZBP1 granules often were observed to enter spine-like protrusions from the dendritic surfaces that were not stained with the MAP2 antibody (Fig. $1 A$, inset, arrow). Labeling of dendritic spines and filopodia was apparent with the use of FITC-phalloidin (Fig. 1 B, green), consistent with observations that filopodia and spines are actin-rich structures (Kaech et al., 1997; Fischer et al., 1998). Dendritic spines (Fig. $1 B$, inset, arrow) were often distinguishable from filopodia (Fig. $1 B$, inset, arrowhead) by the presence of a cap or head at the distal end, which was concentrated with F-actin. ZBP1 granules extended beyond the MAP2-positive (Fig. $1 B$, blue) dendritic shaft and entered both actin-rich filopodia (inset, arrowhead) and spines (inset, arrow). Dendritic spines often were juxtaposed to sites containing synaptophysin, which was distributed in a punctate pattern within axons (Fig. $1 C$, arrows, blue). Synaptic contacts also were observed along the dendritic shaft and cell body.

At this stage of hippocampal culture (2 weeks) the ZBP1 signal within dendrites was much stronger than that observed in axons (data not shown). Using antibody to the axonal marker tau, we have noted the localization of ZBP1 granules in axons, where signal is often prominent at sites of axonal branches and their growth cones (data not shown). In that we have described previously the localization of ZBP1 and $\beta$-actin mRNA in growth cones of developing axons (Zhang et al., 2001), the focus of the present study is on dendrites and spines.

Conventional fluorescence microscopy, even with the aid of a digital camera, has not provided the resolution to determine precisely whether particular mRNAs or mRNA binding proteins are present within dendritic spines and postsynaptic sites. For exam- 
ple, conventional digital imaging has shown that the immunofluorescence signal for $\mathrm{Ca}^{2+} /$ calmodulin-dependent protein kinase II $\alpha$ (CaMKII $\alpha)$ mRNA (Rook et al., 2000) and the mRNA binding protein, cytoplasmic polyadenylation element binding protein (CPEB; Wu et al., 1998), overlapped with presynaptic and postsynaptic markers. The use of image deconvolution and 3-D reconstruction techniques has the potential to determine whether an mRNP is localized to spines and subsynaptic sites by providing the resolution to distinguish presynaptic and postsynaptic compartments. To visualize ZBP (red), synaptophysin (blue), and F-actin (green) at high spatial resolution, we imaged, deconvolved, and reconstructed a $z$-series in three dimensions from the dendritic region shown in Figure $1 C$. A dendritic field is shown by conventional multi-channel imaging with superimposition (Fig. 1C) and then is followed by deconvolution and 3-D reconstruction (Fig. $1 D-F$ ). With the latter approach the presynaptic terminals and boutons (blue) are observed clearly to contact the surface of dendritic spines (green). ZBP1 granules (red) were observed clearly in the dendritic shaft and spine compartment. In large spines (Fig. 1D, left) clusters of ZBP1 granules (red) were observed directly beneath the synaptic contact (blue). The side of the spine lacking the synaptic contact also was lacking in ZBP1. The spatial relationship of ZBP1 to synaptic contacts in spines can be viewed best in three dimensions (video 1, available at www.jneurosci.org).

\section{$\mathrm{KCl}$-induced depolarization stimulated dendritic localization of ZBP1: requirement of NMDA receptors}

To investigate whether the localization of ZBP1 granules in dendrites was regulated by neuronal activity, we added $\mathrm{KCl}$ (20 $\mathrm{mm}$ ) to the medium to depolarize the neurons for $15 \mathrm{~min}$. Neurons then were fixed and processed for immunofluorescence. After $\mathrm{KCl}$ treatment the ZBP1 granules were more abundant within dendrites and more noticeable in distal regions (Fig. $2 A, B$, red). Quantitative digital imaging of ZBP1 immunofluorescence in proximal, middle, and distal regions from 20 stimulated and 20 nonstimulated neurons demonstrated a $19.8 \%$ average increase in mean ZBP1 fluorescence intensities after only $15 \mathrm{~min}$ of $\mathrm{KCl}$ stimulation $(12.3,29.5$, and $17.6 \%$ increases in proximal, middle, and distal regions, respectively; Fig. $2 C$ ). To investigate a role for NMDA receptors in ZBP1 localization, we compared neurons treated with AP-5 (15 min) with those that were stimulated with $\mathrm{KCl}$ and AP-5 (15 min). The presence of AP-5 completely
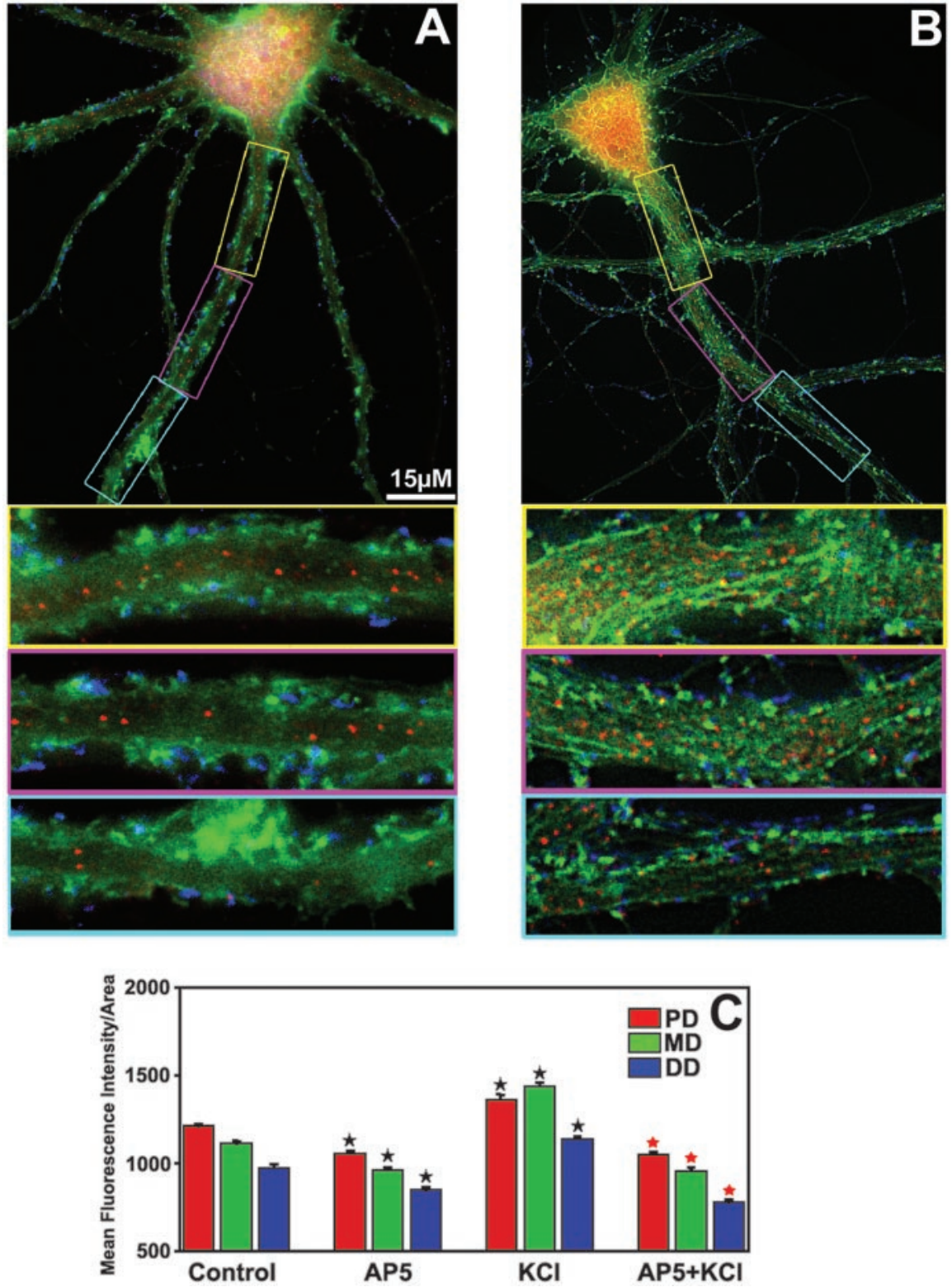

Figure 2. KCl-induced localization of ZBP1 granules in dendrites is dependent on NMDA receptor activity. A, Triple-label fluorescence detection of ZBP1 (red), synaptophysin (blue), and phalloidin (green). The colored boxes overlaid on top of the dendrites show schematically how the dendrite was divided into three regions of interest (proximal, middle, and distal) for performing quantitative digital imaging analysis of pixel intensities with IPLab software (Scanalytics). These three regions have been enlarged at the bottom of each panel by using the same color-coded border. All images were acquired with shorter exposure times than those used in Figure 1, such that the ZBP1 signal in dendrites was sparse and undetectable in distal regions of unstimulated neurons. $B$, The addition of $20 \mathrm{~mm} \mathrm{KCl}$ to the culture medium for $15 \mathrm{~min}$ increased ZBP1 levels in all three dendritic regions as compared with unstimulated neurons. After KCl treatment ZBP1 fluorescence was now apparent in distal regions. $C$, Histogram of mean ZBP1 immunofluorescence intensities for each treatment; 45 dendrites, one per neuron, were analyzed from three experiments. KCl elicited a statistically significant increase in ZBP1 levels (mean 19.8\% increase) as compared with nonstimulated control neurons. The NMDA receptor antagonist AP- 5 completely inhibited the $\mathrm{KCl}$ response. Exposure of neurons to AP-5 alone for 15 min decreased ZBP levels (mean $12.6 \%$ decrease), which was not increased by KCl treatment in the presence of AP-5. Bars show group mean fluorescence intensity/area $\pm \mathrm{SEM} ;{ }^{*} p<0.01$, two-tailed Mann-Whitney $t$ test. Black asterisks denote significance as compared with control untreated neurons. Red asterisks denote significant difference between AP- $5+\mathrm{KCI}$ as compared with $\mathrm{KCl}$ treatment.

blocked the $\mathrm{KCl}$-induced increase in ZBP1 localization in dendrites (Fig. 2C). Neurons treated with AP-5 alone for 15 min also showed a statistically significant reduction in ZBP1 levels in dendrites as compared with untreated control neurons, further evidence for a role of NMDA receptors in $\mathrm{ZBP} 1$ localization in dendrites (Fig. 2C). 

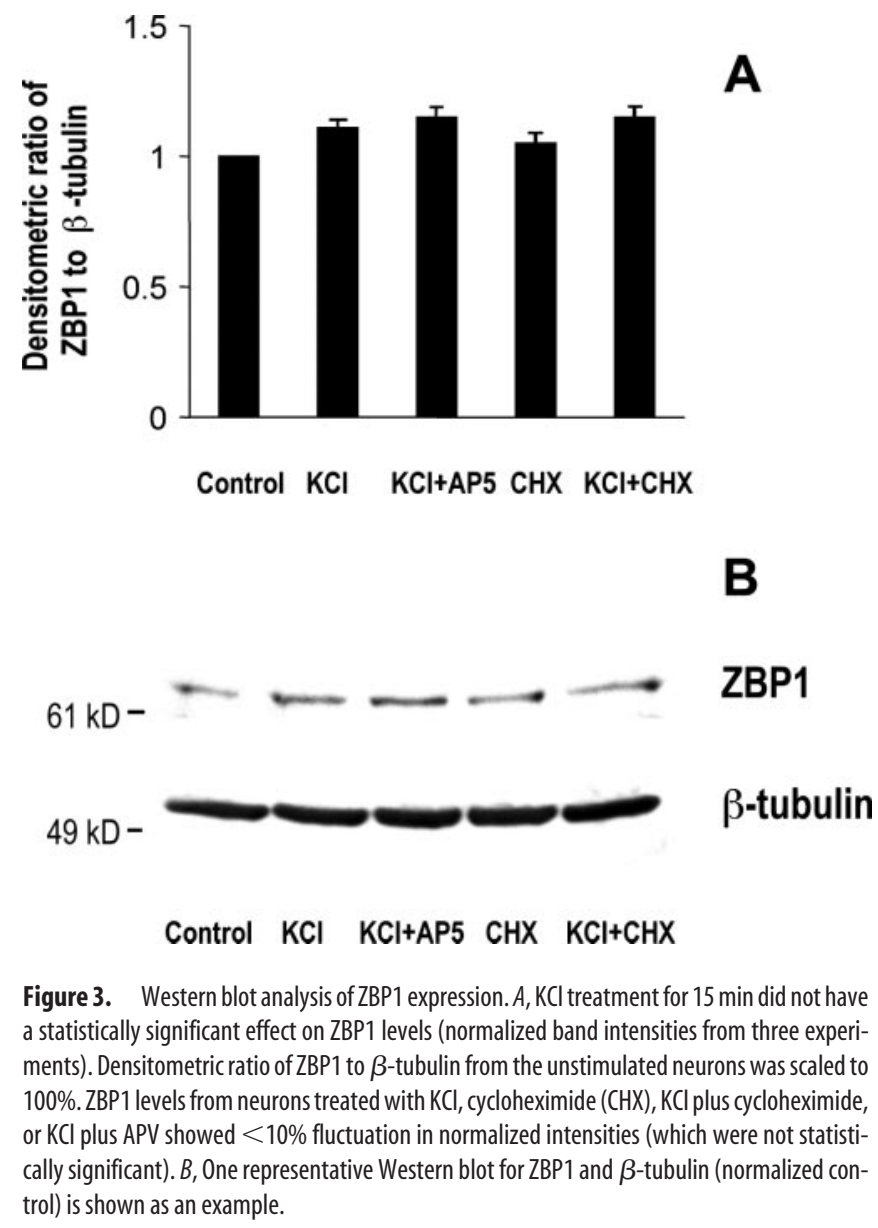

Western blot analyses were performed to determine whether the increase in dendritic ZBP1 levels after $\mathrm{KCl}$-induced depolarization was associated with an overall increase in ZBP1 expression. If ZBP1 expression were stimulated by $\mathrm{KCl}$ treatment $(15$ $\mathrm{min}$ ), an increased band intensity also should be eliminated by previous treatment of cells in a protein synthesis inhibitor. There was no evidence that ZBP1 levels were increased significantly after $15 \mathrm{~min}$ of $\mathrm{KCl}$ exposure (Fig. 3). Quantitative analysis of average ZBP1 band intensities (normalized to $\beta$-tubulin) from three separate experiments did not show any statistically significant increase in ZBP1 levels after a $15 \mathrm{~min} \mathrm{KCl}$ treatment (Fig. $3 A)$. Treatments with either cycloheximide (alone, or with $\mathrm{KCl}$ ) or AP-5 (alone, or with $\mathrm{KCl}$ ) did not result in significant changes $(<10 \%$ fluctuation in all normalized band intensities). These results suggest that the overall $20 \%$ increase in ZBP levels in dendrites, analyzed by quantitative immunofluorescence (Fig. 2), was attributed to the localization of preexisting ZBP1 from the soma after a 15 min treatment with $\mathrm{KCl}$. To address this possibility specifically required that the $\mathrm{KCl}$ stimulation paradigm be performed in live neurons.

\section{Visualization of EGFP-ZBP1 reveals activity-dependent transport and dynamic movements of granules in dendrites and spines}

To test the hypothesis that $\mathrm{KCl}$ depolarization drives the dendritic transport of ZBP1, we directly visualized ZBP1 motility in single live neurons before and after perfusion of $\mathrm{KCl}$. Cultured hippocampal neurons were transiently transfected with a cDNA encoding ZBP1 fused to enhanced green fluorescent protein (EGFP-ZBP1); after $8 \mathrm{hr}$ of expression the transfected neurons were imaged live before and immediately after perfusion with $\mathrm{KCl}$-containing medium (Fig. 4). Perfusion of $\mathrm{KCl}$ was observed to increase EGFP-ZBP1 levels rapidly in dendrites. As early as 5 min after $\mathrm{KCl}$ treatment, increased EGFP-ZBP1 fluorescence was apparent in proximal dendrites (Fig. $4 B$, arrow), with weak signal also observed in more distal dendrites (Fig. $4 B$, arrowhead). Signal continued to increase at proximal and distal sites at $15 \mathrm{~min}$ (Fig. 4C) and $30 \mathrm{~min}$ (Fig. 4D) after $\mathrm{KCl}$ treatment. Quantitative analysis of fluorescence intensities over time (for the neuron imaged in $A-D$ ) revealed an increase in proximal and middle, but not distal, dendrites after a 5 min perfusion of $\mathrm{KCl}$ (Fig. $4 E$ ). Analysis of timed averaged fluorescence intensities for three live neurons (Fig. $4 F$ ) revealed significant increases in proximal $(8 \%)$ and middle (19.3\%) dendrites, but not in distal dendrites (2\%), after $5 \mathrm{~min}$. After $15 \mathrm{~min}$ there were further increases in proximal $(13 \%)$ and middle $(46.9 \%)$ dendrites. In addition, a significant increase now was observed in distal dendrites (14.8\%). After 30 $\mathrm{min}$ in $\mathrm{KCl}$ the dendritic fluorescence intensities were increased to $20.5,61.0$, and $22.2 \%$ in proximal, middle, and distal regions of the dendrites, respectively (average increase of $34.6 \%$ ).

The above imaging paradigm permitted analysis of changes in the overall levels of EGFP-ZBP1 granules in dendritic regions during a $30 \mathrm{~min}$ time period after exposure to $\mathrm{KCl}$. The dynamic movements of individual ZBP1 granules in dendrites necessitated imaging at a faster sampling rate over a shorter time interval, thus facilitating the precise tracking of rapidly moving single granules and a more accurate analysis of their trajectories, motile behavior, and computation of instantaneous velocities. However, it was not possible to image for extended periods of time (i.e., a $\mathrm{KCl}$ time course) because of photobleaching.

Rapid imaging of EGFP-ZBP1 granules over short durations demonstrated mainly three different types of dynamic movements in dendrites (Fig. 5). First, a population of large EGFPZBP1 granules exhibited predominantly oscillatory behavior with no net change in position over time. A second population of granules, both large and small, exhibited bidirectional movements by which a granule would move short distances $(<1 \mu \mathrm{m})$ in one direction and then move back in the other direction. A third type of granule was characterized by unidirectional and persistent movements of long trajectories, either anterograde or retrograde. These trajectories were often as short as $5 \mu \mathrm{m}$, followed by oscillatory or bidirectional movements. However, persistent trajectories occasionally were observed for considerably longer distances $(10-25 \mu \mathrm{m})$.

An EGFP-ZBP1-transfected neuron is shown (Fig. 5A) with a boxed ROI expanded (Fig. $5 B-D$ ) to illustrate examples of retrograde and anterograde trajectories in a dendrite. A long-distance $(25 \mu \mathrm{m})$ retrograde trajectory was analyzed with an average rate of $2.1 \mu \mathrm{m} / \mathrm{sec}$ (Fig. $5 B, C, E$ ). A frame-by-frame analysis of instantaneous velocities for this trajectory often revealed rates of 4.0 $\mu \mathrm{m} / \mathrm{sec}$ of short duration (Fig. $5 E$; see also video 2, available at www.jneurosci.org). This granule moved in a persistent retrograde trajectory for 27 frames and then assumed bidirectional movements in a small area with rates of $<1 \mu \mathrm{m} / \mathrm{sec}$ (Fig. $5 E$ ). A second granule that was tracked exhibited an anterograde trajectory (Fig. $5 B, D, F$ ) with an average rate of $0.2 \mu \mathrm{m} / \mathrm{sec}$ for seven frames, followed by several frames of slower bidirectional movements. This granule was at the slower end of the rates observed for anterograde trajectories, but it was shown to illustrate a broad range of rates and the presence of intermittent or stop-and-go motile behavior. Quantitative frame-by-frame analysis of trajectories for 15 granules indicated a mean granule velocity of 1.2 $\mu \mathrm{m} / \mathrm{sec}$ for anterograde movements and $1.0 \mu \mathrm{m} / \mathrm{sec}$ for retro- 
grade movements (Fig. 5G), demonstrating that ZBP1 granules can exhibit distinct types of motile behavior consistent with fast transport.

In contrast to the granules exhibiting directed movements (analyzed above), the majority of EGFP-ZBP1 granules was not directed, often showing stationary, oscillatory, or wiggly movements with no net direction. These oscillatory granules were observed in the dendritic shaft, filopod, and spines (Fig. 5H,I). Time-lapse analysis depicts the dynamic process of filopodia extension (Fig. $5 \mathrm{H}$ ), and often EGFP-ZBP granules were localized stably to the base of these filopodia for periods of $>10$ sec. In dendritic spines the EGFP$\mathrm{ZBP} 1$ granules were present in both the neck and head and localized stably over time (Fig. 5I). In contrast to these stably localized granules, directed movements of EGFP-ZBP1 granules in the vicinity of spines also were observed. One example is depicted whereby a new granule appears at the base of dendritic spine that contains a stationary granule (Fig. 5I). These results document that, in addition to the rapid and directed trajectories, ZBP1 granules are also capable of stable localization in dendrites, filopodia, and spines.

\section{$\mathrm{KCl}$-induced localization of $\boldsymbol{\beta}$-actin mRNA and its dendritic association with ZBP1}

The activity-dependent trafficking of ZBP1 may influence the dendritic localization of $\beta$-actin mRNA. Previous work in fibroblasts and neurons has shown that ZBP1 binds a $54 \mathrm{nt}$ sequence in the $3^{\prime}$ UTR of $\beta$-actin mRNA and that formation of a ZBP1/ $\beta$-actin mRNP complex is required for localization (Ross et al., 1997; Zhang et al., 2001). Fluorescent in situ hybridization (FISH) was used to detect $\beta$-actin mRNA (red) that revealed punctate staining in dendrites very similar to that observed for ZBP1 (Fig. 6A). $\mathrm{KCl}$ depolarization frequently increased $\beta$-actin mRNA levels in dendrites (Fig. 6B), although quantitative analysis of 45 neurons showed an average increase in dendritic $\beta$-actin mRNA levels of only $12.8 \%$

(Fig. 6E) as compared with $19.8 \%$ for ZBP

(Fig. 2C) after a 15 min exposure to $\mathrm{KCl}$. Treatment with AP-5 alone also decreased $\beta$-actin mRNA levels in dendrites (Fig. $6 C$ ), similar to ZBP (Fig. 2C). In contrast to the immunofluorescence data on ZBP1, the $\mathrm{KCl}$-induced increase in $\beta$-actin mRNA levels in dendrites was blocked only partially by AP-5 (Fig. $6 D, E$ ). This suggests an additional activity-dependent component involved in stabilization or maintenance of dendritic $\beta$-actin mRNA levels that was independent of the NMDA receptor and ZBP1-mediated localization pathway.
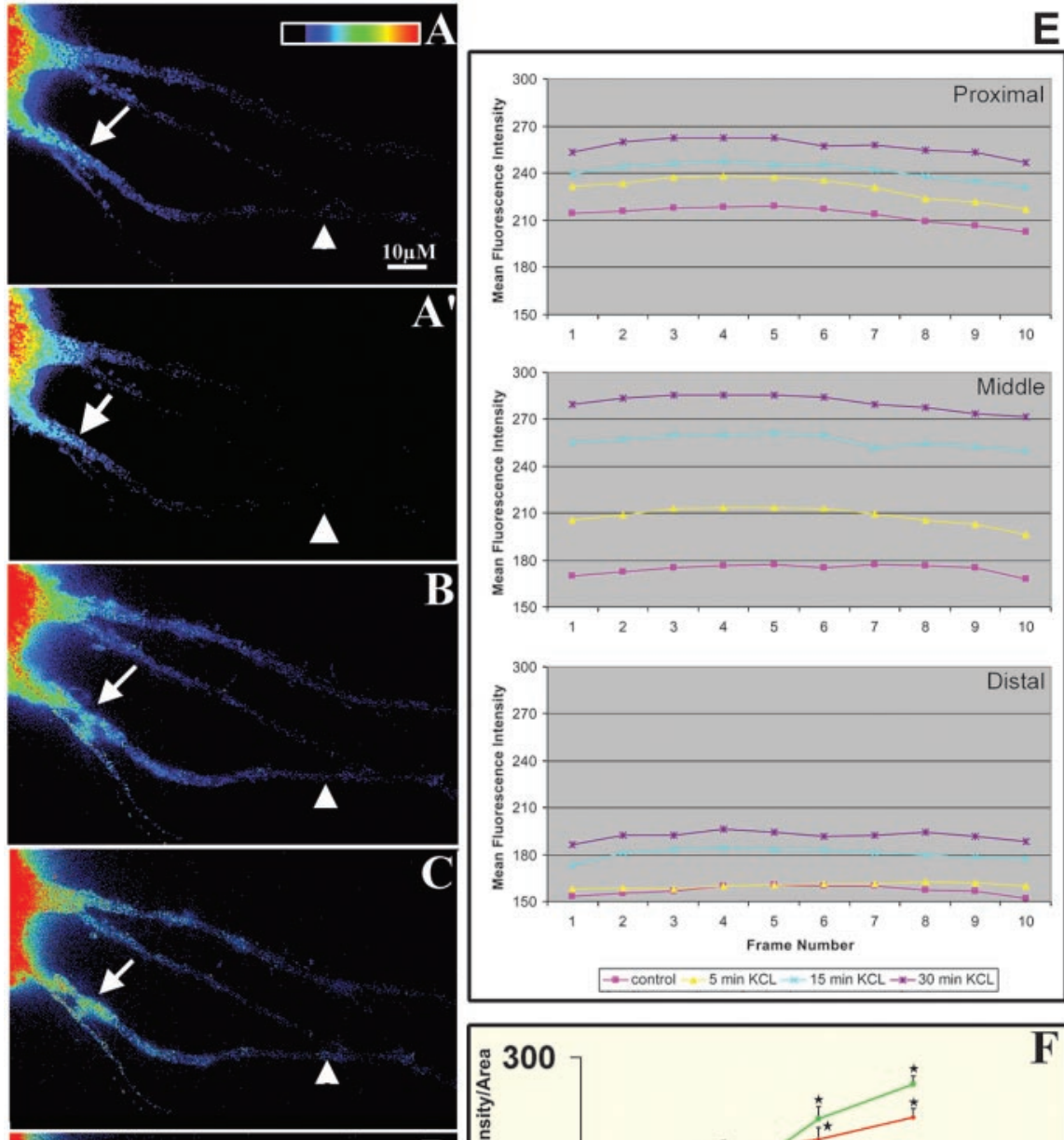

Figure 4. Rapid stimulation of EGFP-ZBP1 granule transport into dendrites visualized in live neurons after $\mathrm{KCl}$ depolarization. Neurons were transfected with EGFP-ZBP1 and imaged live before and after perfusion of $20 \mathrm{mM} \mathrm{KCl}$ containing culture medium. A short time lapse (10 frames) was acquired at $t=0,5,15$, and 30 min after perfusion of KCI. A, EGFP-ZBP1 signal in proximal dendrite (arrow) from frame 1. Intensity was thresholded so no signal was apparent at distal sites (arrowhead). Fluorescence intensity was displayed as a heat-map (inset). $A^{\prime}$, Frame 10 just before $K C l$ perfusion shows comparable signal to Frame 1. B, At 5 min after KCl perfusion there is a marked increase in EGFP-ZBP1 levels at proximal site (arrow; note warmer colors via the heat map). Some weak signal is apparent at a distal site (arrowhead). C, D, EGFP-ZBP1 signals continue to increase at 15 and 30 min time points. $E$, Plot of timed average fluorescence intensities over time for proximal, middle, and distal dendritic regions of the cell imaged in $A-D$. Each of the four time lapses is shown in a different color $(t=0,5,15$, and $30 \mathrm{~min}) . F$, The effects of $\mathrm{KCl}$ perfusion-induced increase in ZBP1 localization were analyzed in three live neurons, and the average fluorescence intensities in each region were plotted over time in $\mathrm{KCl}$.

Although it has been shown from antisense studies that $\beta$-actin mRNA localization is impaired under conditions in which ZBP1 cannot bind the zipcode (Zhang et al., 2001), our previous work did not reveal convincing colocalization between ZBP1 and $\beta$-actin mRNA in neuronal processes (Zhang et al., 2001). One technical problem has been that the antibody to ZBP1 shows weaker labeling after hybridization conditions. Here we have worked to optimize this issue by reducing the formamide concentration by $10 \%$ yet also decreasing the salt concentration so that the hybridization stringency was not changed. Under 

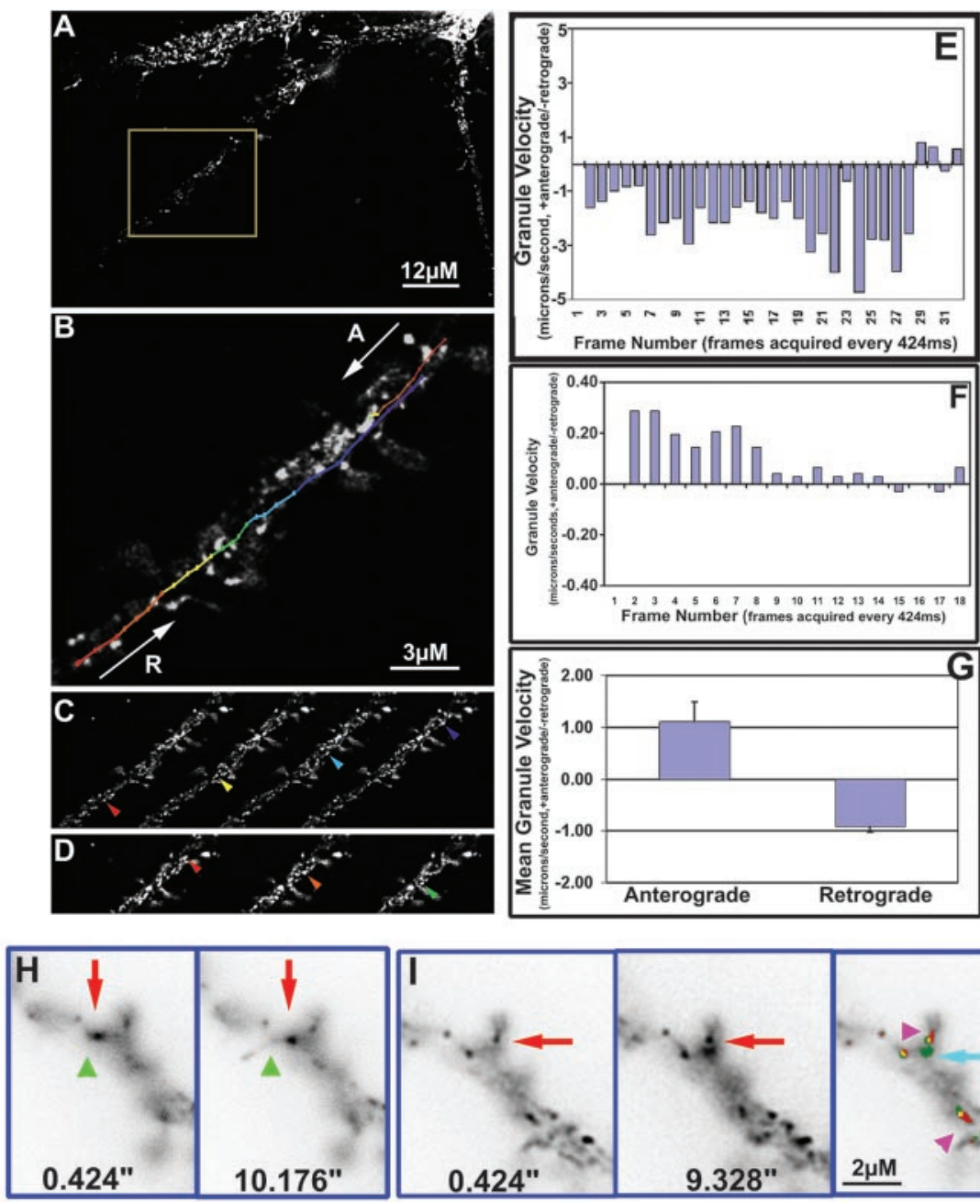

Figure 5. Tracking dynamic movements of single EGFP-ZBP1 granules in dendrites and spines. EGFP-ZBP1 granules are displayed in white for the higher contrast needed for particle tracking. $A$, Transfected neurons showing granules at low magnification. ZBP1 granules from boxed dendritic region are analyzed in detail. $B$, Higher magnification of this subregion revealed many moving granules. The trajectory of a granule moving rapidly in the retrograde ( $R$, arrow) direction was tracked and analyzed frame by frame. The granule trajectory is shown as a heat map (granule moving from red to yellow to green to blue; see also video 2 , available at www.jneurosci.org). Also tracked in this region was a rapidly moving anterograde granule ( $A$, arrow). The granule trajectory is shown as a heat map (granule moving from red to yellow to green; see also video 3, available at www.jneurosci.org). $C, D$, Montage of selected frames from the time lapse for retrograde $(C)$ and anterograde $(D)$ granules. Colored arrows correspond to the heat map trajectories displayed in $B$. $E$, Histogram plots of instantaneous velocities (distance traveled between adjacent frames) for the retrograde granule. $F$, Instantaneous velocities for the anterograde granule. $G$, Average non-zero velocities of anterograde and retrograde granules (trajectories and frame-by-frame analysis for 15 granules that were analyzed). These average velocities included zero values where granules paused during a trajectory. $H$, EGFP-ZBP1 granules frequently observed at sites of dynamic dendritic filopodia. Here a filopodia emerges after 9 sec of time lapse (green arrowhead). I, EGFP-ZBP1 granule observed within a dendritic spine (red arrow). After 9 sec of time lapse a new granule emerges at the base of this spine (green). Granules were pseudo-colored (right panel) to compare pixels that contained ZBP1 in the first frame (red), both frames (yellow), or only in the second frame (green). ZBP1 granules present only in the second frame were attributed to movement of a new granule into the field of view.

these conditions we were able to observe an overlapping, but not highly colocalized, distribution of $\beta$-actin mRNA and ZBP1 granules in dendrites by using conventional digital imaging (Fig. $7 A$ ). To visualize more precisely the spatial relationship between ZBP1 and $\beta$-actin mRNA, we selected two dendritic subregions containing spines (Fig. $7 A$, boxes) for 3 -D reconstruction, using deconvolution and volume rendering of a $z$-series (Fig. $7 B, C$ ). Granules varied in size from small puncta to larger clusters or aggregates and frequently contained both ZBP-1 and $\beta$-actin mRNA within the dendritic shaft and spine.

So that the colocalization between ZBP1 and $\beta$-actin mRNA

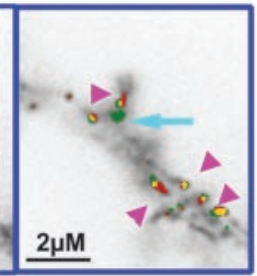

could be quantitated, software was written to interrogate each pixel for the presence of only ZBP signal, the presence of only $\beta$-actin mRNA, or both signals colocalized (Fig. 7D). This quantitative analysis was performed on conventional twodimensional digital images that were thresholded (as in Fig. 7A), but not subjected to volume rendering and 3 -D restoration, which was intended for qualitative visualization. Quantitative colocalization analysis was performed on both unstimulated and $\mathrm{KCl}$-treated neurons. Dendritic subregions were analyzed from 15 stimulated and 15 unstimulated neurons. In unstimulated neurons we observed that $54.2 \%$ (average of proximal, middle, and distal regions) of the $\beta$-actin mRNAlabeled pixels also contained signal for $\mathrm{ZBP} 1$, whereas $32.2 \%$ of the pixels that contained ZBP1 also contained $\beta$-actin mRNA. These data confirmed our qualitative observations that these populations were overlapping, but not highly colocalized. Of interest, $\mathrm{KCl}$ treatment for $15 \mathrm{~min}$ resulted in a significant overall increase (31.7\% average of three regions) in the percentage of ZBP1 pixels that contained $\beta$-actin mRNA signal. $\mathrm{KCl}$ treatment resulted in an overall $11.4 \%$ increase in the percentage of $\beta$-actin mRNA pixels that contained ZBP1 signal. These results indicate that $\mathrm{KCl}$ depolarization can stimulate the spatial association between ZBP1 and $\beta$-actin mRNA in dendrites, the most noted being an increase in the presence of $\beta$-actin mRNA in ZBP granules.

\section{Discussion}

Localization of ZBP1 in dendrites and spines with the use of high-resolution fluorescence imaging

The use of high-resolution fluorescence imaging technology in fixed and live cells has provided new evidence for the localization, dynamic trafficking, and activitydependent regulation of an mRNA binding protein, $\mathrm{ZBP} 1$, in dendrites and postsynaptic sites within dendritic spines of cultured hippocampal neurons. There is a rapidly growing list of mRNA binding proteins that have been localized to dendrites, including fragile X mental retardation protein (FMRP) (Feng et al., 1997), Staufen (Kiebler et al., 1999), CPEB (Wu et al., 1998), and testis-brain RNA binding protein (Severt et al., 1999). Localization of Staufen (Kiebler et al., 1999) and FMRP (Feng et al., 1997) at postsynaptic sites has been achieved by immunoelectron microscopy.

The molecular interactions between mRNA binding proteins and cis-acting mRNA sequences are important for translational regulation and $m R N A$ localization. The binding of CPEB to CPE sequences in the $3^{\prime}$-UTR of CaMKII $\alpha$ mRNA is necessary for experience and NMDA receptor-dependent polyadenylation and 

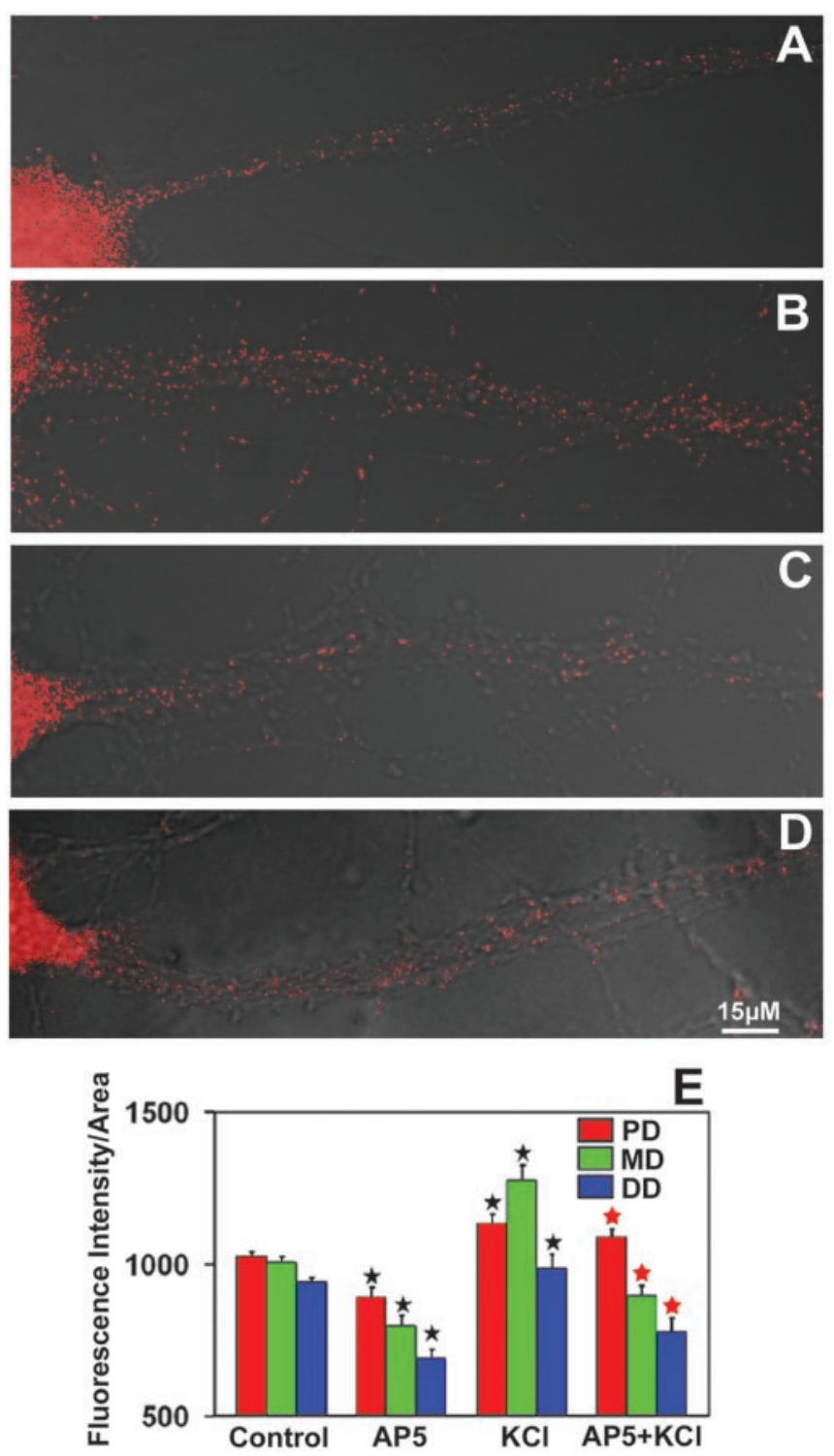

Figure 6. KCl-induced localization of $\beta$-actin mRNA granules. $A$, Localization of $\beta$-actin mRNA granules in dendrites of an unstimulated neuron. $B$, Increased localization of $\beta$-actin mRNA in dendrites $15 \mathrm{~min}$ after $\mathrm{KCl}$ stimulation. $C$, Exposure to the NMDA receptor antagonist AP- 5 reduced the localization of $\beta$-actin mRNA in dendrites. D, Inhibition of NMDA receptor activation with AP-5 in the presence of $\mathrm{KCl}$ did not impair the depolarization-induced localization of $\beta$-actin mRNA in dendrites. E, Quantitative analysis of mean fluorescence intensities from 45 neurons per treatment demonstrated a significant increase in ZBP1 levels after $\mathrm{KCl}$ treatment in proximal, middle, and distal dendritic regions. Treatment of AP-5 alone significantly decreased the localization of $\beta$-actin mRNA as compared with control unstimulated neurons but did not inhibit the KCl-induced increase in $\beta$-actin mRNA. Bars show group means \pm SEM $; p \leq 0.05^{*}$, two-tailed Mann-Whitney $t$ test. Black asterisks denote significance as compared with control untreated neurons. Red asterisks denote comparison of AP-5- and AP-5 + KCl-treated neurons.

translational derepression (Wu et al., 1998; Wells et al., 2001; Huang et al., 2002). This interaction likely occurs at synapses because CPEB colocalized with synaptic markers and was present in fractions of postsynaptic density and synaptosomes (Wu et al., 1998 ) that later were used to demonstrate CPEB-dependent polyadenylation of CaMKII $\alpha$ (Huang et al., 2002).

An mRNA binding protein that is likely to be important for dendritic mRNA localization is the mammalian homolog of Staufen, a Drosophila double-stranded RNA binding protein (Kiebler et al., 1999). Transfection of a Staufen-GFP fusion pro-
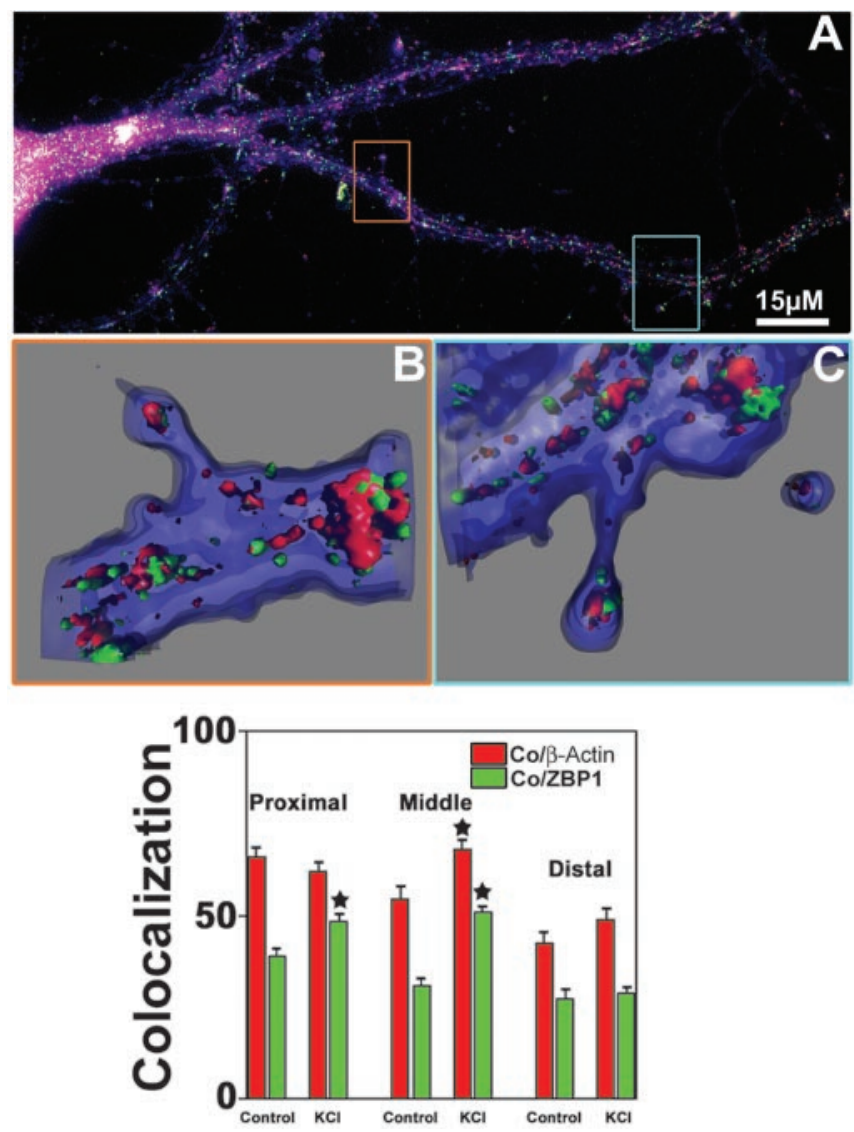

Figure 7. Overlapping distribution between ZBP1 and $\beta$-actin mRNA granules: effects of 15 min KCl depolarization. $A$, Triple-label fluorescence detection of $\beta$-actin mRNA (red), ZBP1 (green), and F-actin, using phalloidin (blue). By conventional digital imaging ZBP1 and $\beta$-actin mRNA both exhibited a granular pattern in dendrites with evidence for overlapping, but not highly colocalized, signals. A3-D deconvolution and volume restoration were performed on two dendritic subregions that appeared to contain ZBP1 and $\beta$-actin mRNA signal in dendritic spines (orange and blue boxes). $B$, Enlargement of orange-boxed region depicts a granule within a bulbous dendritic spine that contains both $\beta$-actin mRNA (red) and ZBP1 (green). In the dendritic shaft the granules containing ZBP1 and $\beta$-actin mRNA varied in size from small puncta to larger clusters or aggregates. C, Enlargement of blue-boxed region also depicts granules that contain both ZBP1 and $\beta$-actin mRNA signal within the spine and shaft (see also video 4 , available at www.jneurosci.org). D, Quantitative colocalization analysis of the spatial relationship between pixels containing ZBP1 (green) and $\beta$-actin mRNA (red). KCl treatment resulted in an overall $31.7 \%$ increase in the percentage of ZBP1 pixels that also contained $\beta$-actin mRNA (green bars), with statistical significance observed in proximal (25\% increase) and middle $(66 \%$ increase) dendritic regions. $\mathrm{KCl}$ treatment resulted in an $11.4 \%$ increase in the percentage of $\beta$-actin mRNA pixels that also contained ZBP1 (red bars), with statistical significance observed in middle dendritic regions (25\% increase). Bars show group means $\pm \mathrm{SEM} ; p \leq$ $0.01 *$, two-tailed Mann-Whitney $t$ test. Black asterisks denote significance as compared with control untreated neurons.

tein into cultured hippocampal neurons has revealed granules exhibiting bidirectional movements along the dendritic shaft that were dependent on microtubules (Kohrmann et al., 1999). Molecular evidence has shown that a dominant-negative form of Staufen can reduce dendritic mRNA content in cultured hippocampal neurons as assayed by fluorescent RNA binding dyes (Tang et al., 2001). One isoform of Staufen was shown to have higher affinity binding to the dendritic targeting element of MAP2 mRNA in vitro (Monshausen et al., 2001), suggesting its possible function in dendritic mRNA localization. Staufen also is enriched in biochemically isolated RNA granules (Krichevsky and Kosik, 2001), structures that transport mRNAs into processes (Ainger et al., 1993; Knowles et al., 1996). It is unknown 
what specific mRNAs are localized in dendrites via a Staufendependent interaction or whether Staufen RNP movements occur within spines.

Here we use high-resolution double-label in situ hybridization and immunofluorescence to visualize the localization of ZBP1 and $\beta$-actin mRNA in dendrites and spines. ZBP1 previously was shown to bind a $54 \mathrm{nt}$ sequence in the $3^{\prime}$-UTR of $\beta$-actin mRNA, an interaction required for mRNA localization to the leading edge of cultured fibroblasts (Ross et al., 1997) and growth cones of developing neurites (Zhang et al., 2001). One shortcoming of the previous study was that it was not possible to show a high level of colocalization between ZBP1 and $\beta$-actin mRNA in processes by using double-label in situ hybridization, immunofluorescence, and conventional digital imaging. Qualitatively, our previous results suggested that there were many ZBP1 granules that did not contain $\beta$-actin mRNA and vice versa (Zhang et al., 2001). Here we have performed 3-D reconstructions of deconvolved sections to visualize more precisely the spatial relationship between ZBP and $\beta$-actin mRNA. This has made it possible to visualize the presence of both $\beta$-actin mRNA and ZBP1 within individual granules in dendrites and spines. Because we observed only $30-50 \%$ colocalization between the two, this does suggest some transient interaction that is important for localization, perhaps regulated by physiological signals to influence mRNA trafficking in dendrites.

\section{Regulation of mRNA localization by neuronal activity and glutamatergic signals}

There have been several technical approaches used previously to analyze the effects of $\mathrm{KCl}$ depolarization on dendritic mRNA localization in cultured neurons. The first approach that was described was to analyze the mean maximal distance of dendritic labeling of the in situ hybridization signal for BDNF and TrkB mRNAs (Tongiorgi et al., 1997). Significant increases in dendritic labeling were apparent after $3 \mathrm{hr}$ of $\mathrm{KCl}$ exposure. Similar observations of increases in the extent of dendritic signal were made for CaMKII $\alpha$ mRNAs after several hours of KCl-induced depolarization (Mori et al., 2000). In the present study we used quantitative immunofluorescence and digital imaging to measure changes in dendritic mRNA levels. This highly sensitive method has allowed us to detect significant increases in ZBP1 and $\beta$-actin mRNA levels as early as $15 \mathrm{~min}$ post- $\mathrm{KCl}$ exposure. This technical advance has allowed for analysis of activity-dependent mRNA localization at earlier time points than previously investigated. These data are important to distinguish rapid localization of preexisting molecules from a somatic pool as opposed to increases in ZBP1 expression. Consistent with this interpretation, we have not observed significant changes in ZBP1 levels by Western blot analysis. Moreover, we observed significant increases in EGFP ZBP1 levels within proximal dendrites of live neurons as early as 5 min post- $\mathrm{KCl}$ treatment.

Quantitative immunofluorescence and FISH analysis indicated that $\mathrm{KCl}$ depolarization increased dendritic levels of ZBP1 and $\beta$-actin mRNA, although to a lesser extent for $\beta$-actin mRNA. In addition, there was a further increase in the number of $\mathrm{ZBP} 1$ granules that contained $\beta$-actin mRNA. One interpretation of these results is that a population of ZBP1 granules may be stimulated to move from the soma into dendrites in a complex with $\beta$-actin mRNA. A further test of this will require methods to visualize ZBP1 and $\beta$-actin mRNA simultaneously in live neurons. An alternative model is that a population of ZBP1 granules that enters the dendrites, in response to $\mathrm{KCl}$, may be deplete of $\beta$-actin mRNA and provides a means to redistribute $\beta$-actin
mRNAs from one site to another within dendrites. Previous work has shown that $\mathrm{KCl}$ can promote a shift from oscillatory to unidirectionally moving granules containing CaMKII $\alpha$ mRNA, suggesting regulation of motility without affecting dendritic mRNA levels (Rook et al., 2000). We speculate that the active transport of mRNA binding proteins such as ZBP1 in response to depolarization could provide a means to move stationary mRNA molecules by tethering them to cytoskeletal motors.

There is an emerging role for specific patterns of activity and glutamatergic signals that can stimulate dendritic mRNA localization in vivo. Both the expression and dendritic localization of mRNA encoding the activity-regulated cytoskeletal protein Arc are induced in the hippocampal dentate gyrus in vivo in response to high-frequency stimulation (Lyford et al., 1995). Arc mRNA was recruited specifically to the band of activated synapses of the middle molecular layer of the dentate gyrus by a mechanism that requires NMDA receptors (Steward et al., 1998).

In this study we show that ZBP1 trafficking is mainly dependent on NMDA receptor signaling. Exposure of cultured neurons to the NMDA receptor antagonist AP-5 decreased ZBP1 levels in dendrites and completely blocked the $\mathrm{KCl}$-induced increase in ZBP1 levels within dendrites. However, although $\beta$-actin mRNA levels in dendrites were reduced by treatment with AP-5 alone (as was ZBP1), the $\mathrm{KCl}$-induced increase in $\beta$-actin mRNA levels was not inhibited entirely by AP-5. These data suggest a possible uncoupling between ZBP1 and $\beta$-actin mRNA. Perhaps a population of $\beta$-actin mRNA may be localized via other mRNA binding proteins in response to $\mathrm{KCl}$ depolarization in a manner that is independent of ZBP1 and NMDA receptors. One possibility is $\mathrm{ZBP} 2$, which is abundant in brain and may compete for binding to the $\beta$-actin zipcode ( $\mathrm{Gu}$ et al., 2002). A ZBP2 homolog, MARTA1, was shown to be localized to dendrites and binds the dendritic targeting element of MAP2 mRNA (Rehbein et al., 2002). Future work is needed to determine whether ZBP2 plays a role in the activity-dependent localization of $\beta$-actin mRNA. Another explanation of why the $\mathrm{KCl}$-induced localization for $\beta$-actin mRNA was not blocked entirely by AP-5, although it is for $\mathrm{ZBP} 1$, could be the presence of another activity-dependent pathway involved in anchoring or translation of $\beta$-actin mRNA in dendrites. The presence of a large population of $\beta$-actin mRNA granules that did not contain ZBP1 may represent mRNAs that are not motile; some may be undergoing translation by polyribosomes. $\mathrm{KCl}$ depolarization may stimulate both the bidirectional movements of ZBP1/ $\beta$-actin mRNP complexes in dendrites (dependence on NMDA receptors) and anchoring and translation of $\beta$-actin mRNA in dendrites (independent of NMDA receptors). The mechanism of anchoring is unclear but could involve dissociation of ZBP1 from the zipcode and sequestration of $\beta$-actin mRNA by polyribosomes. The net effect may be stabilizing $\beta$-actin mRNA in dendrites by removing it from a bidirectional pool that cycles between the soma and dendrites.

\section{Active transport of $\mathrm{ZBP} 1 / \boldsymbol{\beta}$-actin mRNA granules in dendrites and spines may depend on cytoskeletal-based motors}

Several studies have demonstrated an association between microtubules and mRNA (Bassell et al., 1994; Litman et al., 1994) or mRNA binding proteins (Kiebler et al., 1999; Kohrmann et al., 1999; Zhang et al., 2001) in neurons. RNA binding proteins may be important to package mRNAs into larger structures (granules) and also serve as adapter molecules between the mRNA and cytoskeletal-based motors (Bassell and Singer, 2001). Consistent with this hypothesis have been observations of rapid and dy- 
namic movements of mRNAs and mRNA binding proteins. Staufen, when fused to GFP, revealed granules that moved at average anterograde rates of $0.1 \mu \mathrm{m} / \mathrm{sec}$ with maximal rates of 0.4 $\mu \mathrm{m} / \mathrm{sec}$ (Kohrmann et al., 1999). CaMKII $\alpha$ mRNA detected with an MS2 tagging method revealed unidirectional granules that moved in a persistent direction with an average rate of $0.05 \mu \mathrm{m} /$ sec and maximal rates of $0.1 \mu \mathrm{m} / \mathrm{sec}$ (Rook et al., 2000). Our studies on ZBP1 granules reveal considerably faster rates, with average anterograde and retrograde rates of $1.0 \mu \mathrm{m} / \mathrm{sec}$ and maximal rates $>4.0 \mu \mathrm{m} / \mathrm{sec}$. It is possible that ZBP1 granules may interact with different motors; certainly, a wide range of rates has been described for members of the dynein and kinesin superfamily (Hirokawa et al., 1998). Further work may show that ZBP1 has a specific function in microtubule-dependent transport, perhaps serving as an adapter between the $\beta$-actin zipcode and a motor.

In this study we provide new evidence on the motility and dynamics of granules within dendritic spines. We observed ZBP1 granules that were localized stably within individual spines over time as well as new granules that appeared at the base of spines. We speculate that the transition from the dendritic shaft to the actin-rich spine could involve myosin-based movements. Further work on the role of the cytoskeleton and motors in ZBP1 docking at the base of spines or within spines may provide important insight into mechanisms of mRNA delivery to clusters of activated synapses.

\section{Significance of ZBP1-mediated localization of mRNA in dendritic spines}

Dynamics of actin filaments in spines may be important for the regulation of changes in spine morphology that occur during both development and synaptic plasticity (Fischer et al., 1998; Matus, 2000). Actin filaments and actin binding proteins are important for synaptic clustering of glutamate receptors, which could make them important intermediates between the postsynaptic density and underlying cytoskeleton (Allison et al., 1998; Rao and Craig, 2000). Activation of glutamate receptors also can regulate actin dynamics and the morphology of dendritic spines (Fischer et al., 2000). We suggest that ZBP1-mediated transport of $\beta$-actin mRNA and local synthesis of $\beta$-actin may be important for spine maturation and/or regulation of actin-based changes in spine morphology that may underlie certain forms of long-term synaptic plasticity. There may be a critical period during development and synaptogenesis in which $\beta$-actin mRNA localization to synapses, and its regulation by activity, is particularly important for normal maturation of the synapse. Our observations of ZBP1 within dendritic filopodia also suggest a developmental role for ZBP1, because previous reports suggest that dendritic filopodia play an important role in the formation of synaptic contacts and maturation of spines (Ziv and Smith, 1996; Fiala et al., 1998).

Future work is needed to determine the precise role of $\mathrm{ZBP} 1$ in facilitating $\beta$-actin mRNA localization and whether it plays a direct role in transport and/or anchoring. It is also likely that the function of ZBP-mediated mRNA localization extends well beyond $\beta$-actin mRNA and that future identification of ZBP1 target mRNAs may reveal other proteins important for synaptic development and plasticity. The localization of mRNAs in dendrites and spines, and the RNA-protein interactions that govern these dynamics, may provide an important means to regulate local protein synthesis and synaptic plasticity.

\section{References}

Ainger K, Avossa D, Morgan F, Hill SJ, Barry C, Barbarese E, Carson JH (1993) Transport and localization of exogenous myelin basic protein mRNA microinjected into oligodendrocytes. J Cell Biol 123:431-441.

Allison DW, Gelfand VI, Spector I, Craig AM (1998) Role of actin in anchoring postsynaptic receptors in cultured hippocampal neurons: differential attachment of NMDA versus AMPA receptors. J Neurosci 18:2423-2436.

Bagni C, Mannucci L, Dotti CG, Amaldi F (2000) Chemical stimulation of synaptosomes modulates $\alpha$ - $\mathrm{Ca}^{2+} /$ calmodulin-dependent protein kinase II mRNA association to polysomes. J Neurosci 20:RC76(1-6).

Bartlett WP, Banker GA (1984) An electron microscopic study of the development of axons and dendrites by hippocampal neurons in culture. II. Synaptic relationships. J Neurosci 4:1954-1965.

Bassell GJ, Singer RH (2001) Neuronal mRNA localization and the cytoskeleton. In: Cell polarity and subcellular RNA localization (Richter D, ed), pp 41-56. Berlin: Springer.

Bassell GJ, Singer RH, Kosik KS (1994) Association of poly(A) mRNA with microtubules in cultured neurons. Neuron 12:571-582.

Bassell GJ, Zhang HL, Byrd AL, Femino AM, Singer RH, Taneja KL, Lifshitz LM, Herman IM, Kosik KS (1998) Sorting of $\beta$-actin mRNA and protein to neurites and growth cones in culture. J Neurosci 18:251-265.

Chicurel ME, Terrian DM, Potter H (1993) mRNA at the synapse: analysis of a synaptosomal preparation enriched in hippocampal dendritic spines. J Neurosci 13:4054-4063.

Feng Y, Gutekunst CA, Eberhart DE, Yi H, Warren ST (1997) FMRP: nucleocytoplasmic shuttling and association with somatodendritic polyribosomes. J Neurosci 17:1539-1547.

Fiala JC, Feinberg M, Popov V, Harris KM (1998) Synaptogenesis via dendritic filopodia in developing hippocampal area CA1. J Neurosci 18:8900-8911.

Fischer M, Kaech S, Knutti D, Matus A (1998) Rapid actin-based plasticity in dendritic spines. Neuron 20:847-854.

Fischer M, Kaech S, Wagner U, Brinkhaus H, Matus A (2000) Glutamate receptors regulate actin-based plasticity in dendritic spines. Nat Neurosci 3:887-894.

Goslin K, Asmussen H, Banker G (1998) Rat hippocampal neurons in lowdensity culture. In: Culturing nerve cells, 2nd Ed (Banker G, Goslin K, eds), pp 339-371. Cambridge, MA: MIT.

Gu W, Pan F, Zhang HL, Bassell GJ, Singer RH (2002) A predominantly nuclear protein affecting cytoplasmic localization of $\beta$-actin mRNA in fibroblasts and neurons. J Cell Biol 156:41-51.

Harris KM, Kater SB (1994) Dendritic spines: cellular specializations imparting both stability and flexibility to synaptic function. Annu Rev Neurosci 17:341-371.

Hirokawa H, Noda Y, Okada Y (1998) Kinesin and dynein superfamily proteins in organelle transport. Curr Opin Cell Biol 10:60-73.

Huang YS, Jung MY, Sarkissian M, Richter J (2002) NMDA receptor signaling results in Aurora kinase-catalyzed CPEB phosphorylation and $\alpha$-CaMKII mRNA polyadenylation at synapses. EMBO J 21:2139-2148.

Job C, Eberwine J (2001) Localization and translation of mRNA in dendrites and axons. Nat Rev Neurosci 12:889-898.

Kaech S, Fischer M, Doll T, Matus A (1997) Isoform specificity in the relationship of actin to dendritic spines. J Neurosci 17:9565-9572.

Kiebler M, Hemraj I, Verkade P, Kohrmann M, Fortes P, Marion RM, Ortin J, Dotti CG (1999) The mammalian Staufen protein localizes to the somatodendritic domain of cultured hippocampal neurons: implications for its involvement in mRNA transport. J Neurosci 19:288-297.

Kloc MK, Zearfoss NR, Etkin LD (2002) Mechanism of subcellular mRNA localization. Cell 108:533-544.

Knowles RB, Sabry SH, Martone ME, Deerinck TJ, Ellisman MH, Bassell GJ, Kosik KS (1996) Translocation of RNA granules in living neurons. J Neurosci 16:7812-7820.

Kohrmann M, Luo M, Kaether C, DesGroseillers L, Dotti CG, Kiebler MA (1999) Microtubule-dependent recruitment of Staufen-green fluorescent protein into large RNA-containing granules and subsequent dendritic transport in living hippocampal neurons. Mol Biol Cell 10:2945-2953.

Krichevsky AM, Kosik KS (2001) Neuronal RNA granules: a link between RNA localization and stimulation-dependent translation. Neuron 32:683-696.

Litman P, Barg J, Ginzburg I (1994) Microtubules are involved in the local- 
ization of tau mRNA in primary neuronal cell culture. Neuron 13:1463-1474.

Lyford GL, Yamagata K, Kaufmann WE, Barnes CA, Sanders LK, Copeland NG, Gilbert DJ, Jenkins NA, Lanahan AA, Worley PF (1995) Arc, a growth factor and activity-regulated gene, encoded a novel cytoskeletonassociated protein that is enriched in neuronal dendrites. Neuron 14:433-445.

Matus A (2000) Actin-based plasticity in dendritic spines. Science 290:754-758.

Monshausen M, Putz U, Rehbein M, Schweizer M, DesGroseillers L, Kuhl D, Richter D, Kindler S (2001) Two rat brain Staufen isoforms differentially bind RNA. J Neurochem 76:155-165.

Mori Y, Imaizumi K, Katayama T, Yoneda Y, Tohyama M (2000) Two cisacting elements in the $3^{\prime}$-UTR of CaMKII $\alpha$ regulate its dendritic targeting. Nat Neurosci 3:1079-1084.

Rao A, Craig AM (2000) Signaling between the actin cytoskeleton and the postsynaptic density of dendritic spines. Hippocampus 10:527-541.

Rao A, Steward O (1993) Evaluation of RNAs present in synaptodendrosomes. J Neurochem 61:835-844.

Rehbein M, Kindler S, Horke S, Richter D (2000) Two trans-acting rat-brain proteins, MARTA1 and MARTA2, interact specifically with the dendritic targeting element in MAP2 mRNAs. Brain Res Mol Brain Res 79:192-201.

Rehbein M, Wege K, Buck F, Schweizer M, Richter D, Kindler S (2002) Molecular characterization of MARTA1, a protein interacting with the dendritic targeting element of MAP2 mRNAs. J Neurochem 82:1039-1046.

Rook SM, Lu M, Kosik KS (2000) CaMKII $\alpha$ 3'-untranslated regiondirected mRNA translocation in living neurons: visualization by GFP linkage. J Neurosci 20:6385-6393.

Ross A, Oleynikov Y, Kislauskis EH, Taneja KL, Singer RH (1997) Characterization of a $\beta$-actin mRNA zipcode binding protein. Mol Cell Biol 17:2158-2165.

Scheetz AJ, Nairn AC, Constantine-Paton M (2000) NMDA receptormediated control of proteins synthesis at developing synapses. Nat Neurosci 3:211-216.
Severt WL, Biber TU, Xu XQ, Hecht NB, DeLorence RJ, Jakoi ER (1999) The suppression of testis brain RNA binding protein and kinesin heavy chain disrupts mRNA sorting in dendrites. J Cell Sci 112:3691-3702.

Steward O, Schumann EM (2001) Protein synthesis at synaptic sites on dendrites. Annu Rev Neurosci 24:299-325.

Steward O, Worley PF (2001) Selective targeting of newly synthesized Arc mRNA to active synapses requires NMDA receptor activation. Neuron 30:227-240.

Steward O, Wallace C, Lynford G, Worley PF (1998) Synaptic activation causes the mRNA for the IEG Arc to localize selectively near activated postsynaptic sites on dendrites. Neuron 21:741-751.

Tang SJ, Meulemans D, Vazquez L, Colaco N, Schuman EM (2001) A role for a rat homolog of Staufen in the transport of RNA to neuronal dendrites. Neuron 32:463-475.

Tongiorgi E, Righi M, Cattaneo A (1997) Activity-dependent dendritic targeting of BDNF and TrkB mRNAs in hippocampal neurons. J Neurosci 17:9492-9505.

Wells DG, Dong X, Quinlan EM, Huang YS, Bear MF, Richter JD, Fallon JR (2001) A role for the cytoplasmic polyadenylation element in NMDA receptor-regulated mRNA translation in neurons. J Neurosci 21:9541-9548.

Wu L, Wells D, Tay J, Mendis D, Abbott MA, Barnitt A, Quinlan E, Heynen A, Fallon JR, Richter JD (1998) CPEB-mediated cytoplasmic polyadenylation and the regulation of experience-dependent translation of $\alpha$-CaMKII mRNA at synapses. Neuron 21:1129-1139.

Zhang HL, Singer RH, Bassell GJ (1999) Neurotrophin regulation of $\beta$-actin mRNA and protein localization within growth cones. J Cell Biol 147:59-70.

Zhang HL, Eom T, Oleynikov Y, Shenoy S, Liebelt DA, Dictenberg JB, Singer RH, Bassell GJ (2001) Neurotrophin-induced transport of a $\beta$-actin mRNP complex increases $\beta$-actin levels and stimulates growth cone motility. Neuron 31:261-275.

Ziv NE, Smith SJ (1996) Evidence for a role of dendritic filopodia in synaptogenesis and spine formation. Neuron 17:91-102. 